\title{
Long-Term Outcomes of Radical Surgery for Transverse Colon Cancer Staged from I to IIIC
}

This article was published in the following Dove Press journal:

Cancer Management and Research

\author{
Yaofei Jiang ${ }^{1,2, *}$ \\ Zhenhong Zou',* \\ Zulei Zhang $\mathbb{D}^{1,3, *}$ \\ Yi Zhang ${ }^{l, *}$ \\ Yuting Sun' \\ Bo Liang'
}

'Department of General Surgery, The Second Affiliated Hospital of Nanchang University, Nanchang, Jiangxi, People's

Republic of China; ${ }^{2}$ Hubei Key Laboratory of Tumor Biological Behaviors, Zhongnan Hospital, Wuhan University, Wuhan, Hubei Province, People's Republic of China; ${ }^{3}$ Department of Cardiac Surgery, Ganzhou People's Hospital, Ganzhou, Jiangxi, People's Republic of China

*These authors contributed equally to this work
Correspondence: Bo Liang

Department of General Surgery, The Second Affiliated Hospital of Nanchang University, Nanchang, Jiangxi 330006,

People's Republic of China

Email 1690960497@qq.com
Background: No study has reported the risk factors associated with the prognosis of patients with transverse colon cancer. Therefore, we aimed to demonstrate the long-term outcomes of transverse colon cancer patients undergoing radical surgery and explore the prognostic factors.

Materials and Methods: The clinical data of a total of 366 patients with transverse colon cancer staged from I to IIIC undergoing radical surgery from February 1992 to May 2017 were retrospectively analyzed. Clinicopathological features were recorded, and univariate and multivariate analyses were conducted to evaluate the association between the factors and overall survival (OS) as well as disease-free survival (DFS). Kaplan-Meier curves were generated to assess the association between TNM stage and OS and DFS, respectively.

Results: The median follow-up time was 62 months, and the 5-year OS and DFS rates were $87.5 \%$ and $86.5 \%$, respectively. In addition, a significant difference was also found in the OS and DFS curves according to TNM stage. The $\mathrm{N}$ classification, vascular invasion, differentiation, preoperative CA199, preoperative CA125 and preoperative AFP were significantly associated with OS according to univariate analysis, while $\mathrm{N}$ classification and differentiation were independent prognostic factors for OS according to multivariate analysis (both $P<$ 0.05). Similarly, N classification, vascular invasion, differentiation, preoperative CA199, preoperative CA125, and preoperative AFP were statistically correlated with DFS according to univariate analysis, while $\mathrm{N}$ classification and preoperative CA199 were independent prognostic factors for DFS according to multivariate analysis (both $P<0.05$ ).

Conclusion: $\mathrm{N}$ classification was an independent factor for both OS and DFS, while differentiation and CA199 were independent prognostic factors only for OS and DFS, respectively.

Keywords: transverse colon cancer, radical surgery, risk factor

\section{Introduction}

Colorectal cancer (CRC) is a common malignancy that severely threatens the health of the population and increases the financial burden of the families and the country of cancer patients. It is the fourth most common cancer in the world and the second leading cause of cancer-related death in the west. ${ }^{1}$ Although the majority of patients are diagnosed between 50 and 70 years of age, the incidence of colorectal cancer in the younger population is increasing in recent years and the younger patients have lower survival. ${ }^{2,3}$ Many other studies have investigated the prognostic factors of colorectal cancer, including the number of lymph nodes examined, ${ }^{4,5}$ oncogenes, ${ }^{6}$ and correlated miRNAs. ${ }^{7,8}$

However, few studies have reported data on transverse colon cancer as a separate category. The reason is that transverse colon cancer is less frequent than other colon 
cancers, including rectal cancer, sigmoid colon cancer, cecum cancer, or right and left colon cancer. Few published studies have reported the long-term oncological outcomes specifically in transverse colon cancer. So far, no study has analyzed the risk factor for the long-term prognosis of transverse colon cancer patients. Thus, the purpose of our study was to explore the association between clinicopathological characteristics and the prognosis of transverse colon cancer patients undergoing radical surgery at stages from I to IIIC based on multicenter databases.

\section{Materials and Methods}

Data of patients who underwent radical surgery from February 2, 1992 to May 16, 2017 were collected from three Affiliated Hospitals of Nanchang University. Patients with metastasis and those who received emergency surgery due to obstruction, perforation or hemorrhage or were lost to follow-up were excluded from the analysis. Then, 15 patients with stage IV transverse colon cancer and 5 patients who received palliative surgery were excluded. Thus, a total of 366 patients in stages from I to IIIC were included in our study. The protocol of this study was reviewed and approved by the Medical Ethics Committee of The Second Affiliated Hospital of Nanchang University. Ethics Committee approved oral informed consent. Informed consent was obtained orally from the included patients by telephone and was approved by the Medical Ethics Committee of The Second Affiliated Hospital of Nanchang University and that your study complied with the Declaration of Helsinki.

The cancer stage was classified according to the 7 th pathological TNM staging system of the AJCC. ${ }^{9}$ Radical surgery was identified as a procedure with no residual tumor left at the resection margins under microscopical observation. $^{3}$

Transverse colon cancer includes cancer arising between the hepatic and splenic flexures. For the enrolled 366 patients, the following information was obtained: gender, age, TNM stage, $\mathrm{T}$ classification, $\mathrm{N}$ classification, tumor size, cancer nodules, perineural invasion, vascular invasion, differentiation, American Society of Anesthesiologists score (ASA score: I, healthy; II, mild systemic disorder; III, severe systemic disorder; IV, severe systemic disorder with threat to life; and V, state of illness sufficiently dire so as to indicate death within 24 hours without surgical intervention), preoperative tumor serum markers including carbohydrate antigen 199 (CA199), carbohydrate antigen 125 (CA125),
Table I Clinicopathological Characteristics of Patients

\begin{tabular}{|c|c|c|}
\hline Characteristics & & Number of Cases (\%) \\
\hline \multirow[t]{3}{*}{ Age $(y)$} & & \\
\hline & $\geq 60$ & $172(47)$ \\
\hline & $<60$ & $194(53)$ \\
\hline \multirow[t]{3}{*}{ Gender } & & \\
\hline & Male & $188(51.4)$ \\
\hline & Female & $178(48.6)$ \\
\hline \multirow[t]{7}{*}{ TNM stage } & & \\
\hline & I & $18(4.9)$ \\
\hline & IIA & $67(18.3)$ \\
\hline & IIB & $156(42.6)$ \\
\hline & IIC & $19(5.2)$ \\
\hline & IIIB & $72(19.7)$ \\
\hline & IIIC & $34(9.3)$ \\
\hline \multirow[t]{5}{*}{ T classification } & & \\
\hline & TI & $5(1.4)$ \\
\hline & $\mathrm{T} 2$ & $12(3.3)$ \\
\hline & $\mathrm{T} 3$ & $84(23)$ \\
\hline & T4 & $264(72.3)$ \\
\hline \multirow[t]{4}{*}{$\mathrm{N}$ classification } & & \\
\hline & No & $260(71)$ \\
\hline & $\mathrm{NI}$ & $77(21)$ \\
\hline & N2 & $29(7.9)$ \\
\hline \multirow[t]{3}{*}{ Tumor size $(\mathrm{cm})$} & & \\
\hline & $\geq 6$ & $153(4 \mid .8)$ \\
\hline & $<6$ & $213(58.2)$ \\
\hline \multirow[t]{3}{*}{ Cancer nodules } & & \\
\hline & Positive & $39(10.7)$ \\
\hline & Negative & $327(89.3)$ \\
\hline \multirow[t]{3}{*}{ Perineural invasion } & & \\
\hline & Positive & $29(7.9)$ \\
\hline & Negative & $337(92.1)$ \\
\hline \multirow[t]{3}{*}{ Vascular invasion } & & \\
\hline & Positive & $25(6.8)$ \\
\hline & Negative & $34 \mid(93.2)$ \\
\hline \multirow[t]{4}{*}{ Differentiation } & & \\
\hline & Well & $10(2.7)$ \\
\hline & Moderate & $296(81.1)$ \\
\hline & Poor & $59(16.2)$ \\
\hline \multirow[t]{4}{*}{ ASA score } & & \\
\hline & I & $47(12.8)$ \\
\hline & II & $28 I$ (76.8) \\
\hline & III & $38(10.4)$ \\
\hline \multirow[t]{3}{*}{ CA199 (ug/L) } & & \\
\hline & $\geq 37$ & $72(19.8)$ \\
\hline & $<37$ & $292(80.2)$ \\
\hline
\end{tabular}

(Continued) 
Table I (Continued).

\begin{tabular}{|l|l|l|}
\hline Characteristics & & Number of Cases (\%) \\
\hline CAI25 (ug/L) & & \\
& $\geq 35$ & $31(8.5)$ \\
& $<35$ & $335(91.5)$ \\
\hline CEA (ug/L) & & \\
& $\geq 5$ & $121(33.1)$ \\
& $<5$ & $245(66.9)$ \\
\hline AFP (ug/L) & & $2(0.6)$ \\
& $\geq 25$ & $361(99.4)$ \\
\hline
\end{tabular}

Abbreviation: ASA, American Society of Anesthesiologists.

carcinoembryonic antigen binding protein (CEA) and alphafetoprotein receptor (AFP). The deadline for the follow-up was May 2018. The mean follow-up time was 70.3 months. Follow-up information was collected from medical records, telephone calls or house visits.

All variables were converted into classification variables and presented as numbers and percentages. The cutoff value for age distribution was 60 years, $6 \mathrm{~cm}$ for tumor size, $37 \mu \mathrm{g} / \mathrm{L}$ for CA199, $35 \mu \mathrm{g} / \mathrm{L}$ for CA125, $5 \mu \mathrm{g} / \mathrm{L}$ for CEA, $25 \mu \mathrm{g} / \mathrm{L}$ for AFP, as many previous studies. ${ }^{10-13}$ Other variables were classified according to their character.

\section{Statistical Analysis}

The chi-squared test was used to assess the significance of baseline differences and the Kaplan-Meier method was used to calculate the rates of overall and disease-free survival. The prognostic factors and survival rates were compared using the Log rank test. Univariate and multivariate analyses were conducted using the Cox model. Differences with $P$-values of less than 0.05 in a twotailed test were considered statistically significant. SPSS software (version 21.0; IBM Corp, USA) was used to perform all statistical analyses.

\section{Results}

The evaluated clinicopathological characteristics are listed in Table 1. Among the 366 patients enrolled in total, 194 (53\%) were younger than 60 years and $188(51.4 \%)$ were male. Eighteen (4.9\%), 67 (18.3\%), 156 (42.6\%), 19 (5.2\%), 72

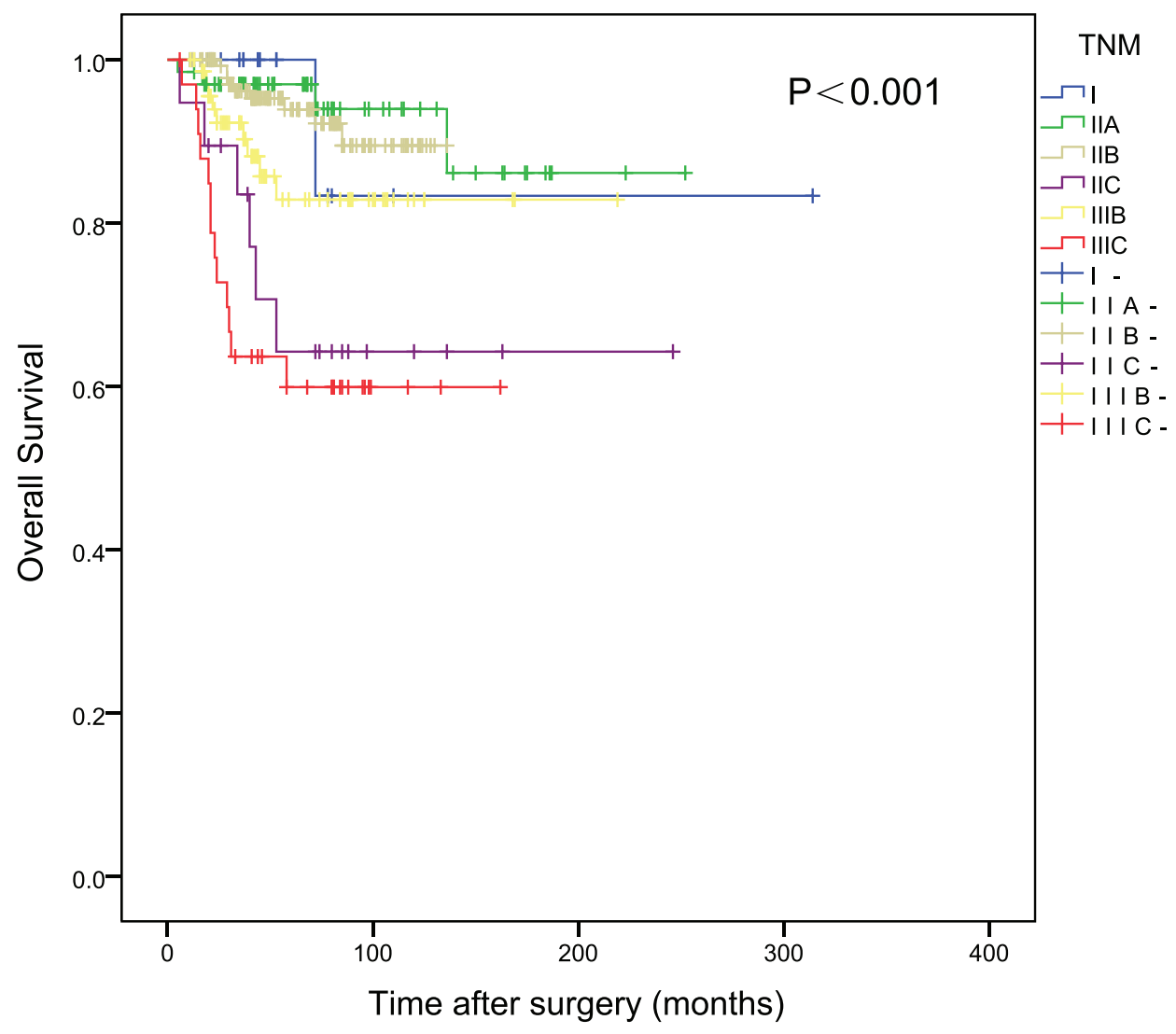

Figure I Overall survival of patients with transverse colon cancer according to TNM stage. 


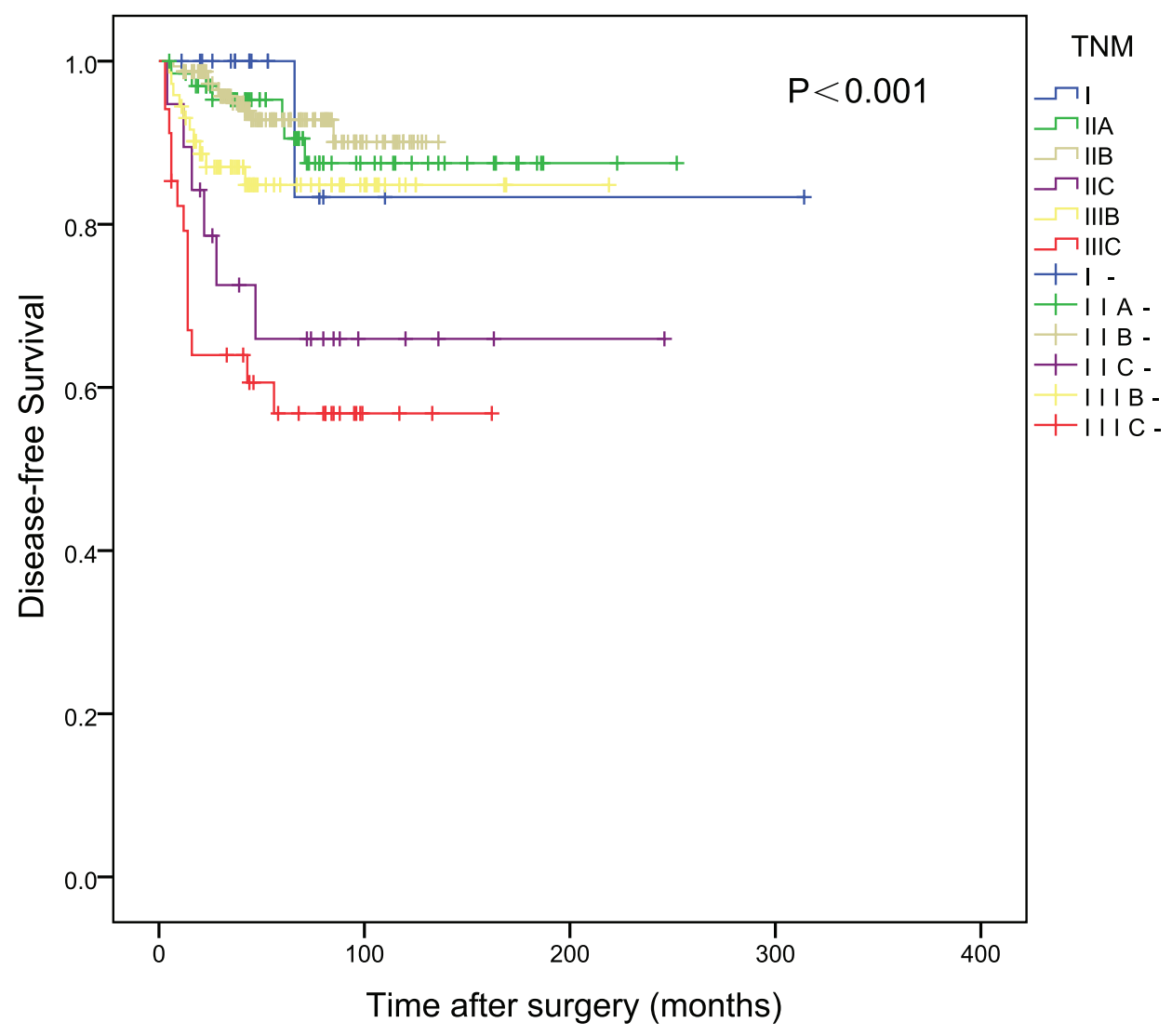

Figure 2 Disease-free survival of patients with transverse colon cancer according to TNM stage.

(19.7\%), and $34(9.3 \%)$ patients were at TNM stages I, IIA, IIB, IIC, IIIB and IIIC, respectively. One hundred and fiftythree (41.8\%) patients had tumor size greater than or equal to $6(\mathrm{~cm})$. In addition, $39(10.7 \%), 29(7.9 \%)$, and $25(6.8 \%)$ of the patients had cancer nodules, perineural invasion, and vascular invasion, respectively. The pathological differentiation degree of tumors from $10(2.7 \%)$ patients was recognized as well differentiated, while 296 (81.1\%) were classified as moderate, and $59(16.2 \%)$ as poor. The ASA scores of 47 (12.8\%), 281 (76.8\%), and 38 (10.4\%) patients were I, II and III, respectively. According to their cut-off values, 72 (19.8\%), 31 (8.5\%), 121 (33.1\%), and $2(0.6 \%)$ patients had positive expression of preoperative CA199, CA125, CEA and AFP, respectively.

The median follow-up time was 62 months, ranging from 11 months to 302 months. In terms of oncological outcomes, the 5-year OS and DFS rates for transverse colon cancer patients undergoing radical resection were $87.5 \%$ and $86.5 \%$, respectively. The overall survival curves among stages, including I, IIA, IIB, IIC, IIIB, and IIIC differed significantly $(P<0.001$, Figure 1$)$. Significant differences were also found in the disease-free survival curves among the TNM stage ( $P<0.001$, Figure 2$)$. As shown in Table 2, the univariate analysis revealed that $\mathrm{N}$ classification $(\mathrm{HR}=2.441$, 95\% CI: $1.686-3.534)$, vascular invasion ( $\mathrm{HR}=0.270,95 \%$ CI: $0.125-0.584)$, differentiation ( $\mathrm{HR}=2.688,95 \%$ CI: 1 .458-4.956), preoperative CA199 (HR $=0.375,95 \%$ CI: 0.199-0.705), CA125 (HR $=0.425,95 \%$ CI: $0.188-0.958)$ and AFP (HR $=0.104,95 \%$ CI: $0.014-0.764)$ had statistically significant associations with OS. The multivariate analysis indicated that $\mathrm{N}$ classification $(\mathrm{HR}=1.909,95 \%$ CI: $1.248-2.920)$ and differentiation ( $\mathrm{HR}=2.153,95 \% \mathrm{CI}$ : 1.141-4.062) were independent prognostic factors for OS. Similarly, N classification $(\mathrm{HR}=2.445,95 \% \mathrm{CI}: 1.714$ 3.488), vascular invasion ( $\mathrm{HR}=0.243,95 \% \mathrm{CI}: 0.117-0.503$ ), differentiation ( $\mathrm{HR}=2.205,95 \% \mathrm{CI}: 1.208-4.024)$, preoperative CA199 (HR $=0.371,95 \%$ CI: $0.205-0.674)$, preoperative CA125 (HR $=0.423,95 \%$ CI: 0.198-0.905), and preoperative AFP (HR $=0.125,95 \%$ CI: $0.017-0.914)$ showed statistically significant correlations with DFS according to univariate analysis, while $\mathrm{N}$ classification (HR $=1.987,95 \%$ CI: $1.306-$ $3.025)$ and preoperative CA199 level (HR $=0.524,95 \% \mathrm{CI}$ : 0.275-0.996) were independent prognostic factors for DFS according to multivariate analysis. 
Table 2 Prognostic Factors for Overall and Disease-Free Survival $(n=366)$

\begin{tabular}{|c|c|c|c|c|c|c|c|c|c|}
\hline & & \multicolumn{4}{|l|}{ os } & \multicolumn{4}{|l|}{ DFS } \\
\hline & & \multirow{2}{*}{$\begin{array}{l}\text { Univariate } \\
\text { HR }(95 \% \mathrm{Cl})\end{array}$} & \multirow[t]{2}{*}{$\mathbf{P}$} & \multirow{2}{*}{$\begin{array}{l}\text { Multivariate } \\
\text { HR }(95 \% \mathrm{Cl})\end{array}$} & \multirow[t]{2}{*}{$P$} & \multirow{2}{*}{$\begin{array}{l}\text { Univariate } \\
\text { HR }(95 \% \mathrm{Cl})\end{array}$} & \multirow[t]{2}{*}{$P$} & \multirow{2}{*}{$\begin{array}{l}\text { Multivariate } \\
\text { HR }(95 \% \mathrm{Cl})\end{array}$} & \multirow[t]{2}{*}{$\mathbf{P}$} \\
\hline & & & & & & & & & \\
\hline Age (y) & $\begin{array}{l}\geq 60 \\
<60\end{array}$ & $0.616(0.335-1.135)$ & 0.120 & & & $0.994(0.558-1.770)$ & 0.984 & & \\
\hline Gender & $\begin{array}{l}\text { Male } \\
\text { Female }\end{array}$ & $1.046(0.571-1.918)$ & 0.884 & & & $1.077(0.607-1.910)$ & 0.799 & & \\
\hline T classification & $\begin{array}{l}\text { TI } \\
\text { T2 } \\
\text { T3 } \\
\text { T4 }\end{array}$ & $1.494(0.804-2.779)$ & 0.204 & & & $1.457(0.817-2.600)$ & 0.202 & & \\
\hline $\mathrm{N}$ classification & $\begin{array}{l}\text { No } \\
\text { NI } \\
\text { N2 }\end{array}$ & $2.44 I$ (I.686-3.534) & $<0.001$ & $1.909(1.248-2.920)$ & 0.003 & $2.445(1.714-3.488)$ & $<0.001$ & $1.987(1.306-3.025)$ & 0.001 \\
\hline Tumor size $(\mathrm{cm})$ & $\begin{array}{l}\geq 6 \\
<6\end{array}$ & $0.947(0.514-1.746)$ & 0.862 & & & $1.039(0.58-1.860)$ & 0.898 & & \\
\hline Cancer nodules & $\begin{array}{l}\text { Positive } \\
\text { Negative }\end{array}$ & $0.778(0.306-1.981)$ & 0.599 & & & $0.905(0.358-2.289)$ & 0.833 & & \\
\hline Perineural invasion & $\begin{array}{l}\text { Positive } \\
\text { Negative }\end{array}$ & $0.532(0.224-1.265)$ & 0.153 & & & $0.493(0.221-1.102)$ & 0.085 & $1.160(0.457-2.946)$ & 0.754 \\
\hline Vascular invasion & $\begin{array}{l}\text { Positive } \\
\text { Negative }\end{array}$ & $0.270(0.125-0.584)$ & 0.001 & $0.736(0.294-1.840)$ & 0.512 & 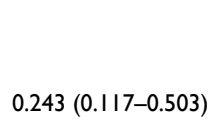 & $<0.001$ & 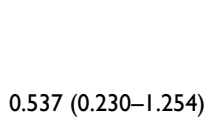 & 0.151 \\
\hline Differentiation & $\begin{array}{l}\text { Well } \\
\text { Moderate } \\
\text { Poor }\end{array}$ & $2.688(1.458-4.956)$ & 0.002 & $2.153(1.14 \mid-4.062)$ & 0.018 & $2.205(1.208-4.024)$ & 0.010 & $1.743(0.935-3.249)$ & 0.080 \\
\hline ASA & $\begin{array}{l}1 \\
2 \\
3\end{array}$ & $1.598(0.83 \mathrm{I}-3.072)$ & 0.160 & & & $1.159(0.626-2.146)$ & 0.640 & & \\
\hline CA199 (ug/L) & $\begin{array}{l}\geq 37 \\
<37\end{array}$ & $0.375(0.199-0.705)$ & 0.002 & 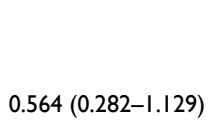 & 0.106 & 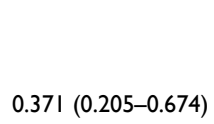 & 0.001 & 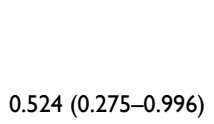 & 0.049 \\
\hline CAI25 (ug/L) & $\begin{array}{l}\geq 35 \\
<35\end{array}$ & $0.425(0.188-0.958)$ & 0.039 & $1.001(0.396-2.529)$ & 0.998 & $0.423(0.198-0.905)$ & 0.027 & $1.005(0.4 \mid 4-2.442)$ & 0.991 \\
\hline CEA (ug/L) & $\begin{array}{l}\geq 5 \\
<5\end{array}$ & $0.880(0.483-1.602)$ & 0.675 & & & $1.003(0.575-1.749)$ & 0.992 & & \\
\hline
\end{tabular}

(Continued) 
Table 2 (Continued).

\begin{tabular}{|c|c|c|c|c|c|c|c|c|c|}
\hline & & \multicolumn{4}{|l|}{ OS } & \multicolumn{4}{|l|}{ DFS } \\
\hline & & Univariate & $P$ & Multivariate & $P$ & Univariate & $P$ & Multivariate & $P$ \\
\hline & & HR (95\% Cl) & & HR (95\% Cl) & & HR (95\% Cl) & & HR (95\% Cl) & \\
\hline AFP (ug/L) & $\begin{array}{l}\geq 25 \\
<25\end{array}$ & $0.104(0.014-0.764)$ & 0.026 & $0.449(0.048-4.206)$ & 0.483 & $0.125(0.017-0.914)$ & 0.040 & $0.744(0.079-6.990)$ & 0.795 \\
\hline
\end{tabular}

Abbreviations: OS, overall survival; DFS, disease-free survival; HR, hazard ratios; $\mathrm{Cl}$, confidence interval; ASA, American Society of Anesthesiologists.

\section{Discussion}

Transverse colon cancer is a tumor located between the hepatic and splenic flexure of the colon. The incidence of transverse colon cancer is relatively low, accounting for only about $10 \%$ of all colorectal cancer cases. ${ }^{14,15}$ Although colorectal cancer has been well studied, ${ }^{16-19}$ there are few studies on specifically transverse colon cancer, and there are even fewer studies on the long-term outcomes of transverse colon cancer patients who underwent radical surgery. To our best knowledge, this is the first study to analyze the risk factors for the long-term prognosis of transverse colon cancer.

Here, we retrospectively analyzed 366 transverse colon cancer cases staged from I to IIIC to explore the prognosis of transverse colon cancer patients undergoing radical surgery. The median follow-up time was 62 months, and the 5-year OS and DFS rates were $87.5 \%$ and $86.5 \%$, respectively. In addition, significant differences were also found in the OS and DFS curves according to the TNM stage. $\mathrm{N}$ classification, vascular invasion, differentiation, preoperative CA199, preoperative CA125 and preoperative AFP were significantly associated with OS according to univariate analysis, while $\mathrm{N}$ classification and differentiation were independent prognostic factors for OS according to multivariate analysis (both $P<0.05$ ). Similarly, $\mathrm{N}$ classification, vascular invasion, differentiation, preoperative CA199, preoperative CA125, and preoperative AFP were found to be related to the DFS according to univariate analysis, while $\mathrm{N}$ classification and the preoperative CA199 level were independent prognostic factors for DFS according to multivariate analysis (both $P<0.05$ ).

Noticeably, Cox analysis did not show T classification influence on prognosis, although TNM stage and $\mathrm{N}$ stage both have a significant influence on prognosis. It is different from most previous studies on colon cancer which reported that advanced $\mathrm{T}$ classification predicts poor prognosis. The reasons may be the relatively small sample size of patients or it is the definite situation in transverse colon cancer. We could not draw a firm conclusion about this because the present study firstly analyzed the risk factors for the long-term prognosis of transverse colon cancer solely. Prospective studies with a larger sample size and higher-quality are needed to identify this finding.

Among the available studies on transverse colon cancer, this study has the biggest sample size. Moreover, the follow-up period of our study was long enough to calculate the 5-year survival rates. In addition, this study is a multi-center retrospective study. Most importantly, no previous study analyzed the risk factor for the long-term prognosis of transverse colon cancer.

However, our study has some limitations. Firstly, the findings are limited by the retrospective nature of the analyses, as well as potential selection bias. Secondly, the accuracy of cumulative overall and disease-free survival rates according to tumor stages was limited by a relatively small number of cases in each stage. Finally, the data are collected over a long timeframe. Although all patients' stage as re-classified according to the 7th pathological TNM staging system of the AJCC, the advanced therapy and more accurate staging inevitably bring bias for the correlated results. Further prospective studies with a larger sample size and higher quality are needed to explore the risk factors influencing the long-term prognosis in patients with transverse colon cancer undergoing radical surgery.

\section{Conclusions}

Ultimately, our study demonstrated that $\mathrm{N}$ classification and differentiation are independent prognostic factors for OS, while $\mathrm{N}$ classification and the preoperative CA199 level are independent prognostic factors for DFS. The results of this study provide a meaningful theoretical basis for the prognosis and assessment of the recurrence risk in patients with transverse colon cancer. 


\section{Author Contributions}

All authors made substantial contributions to conception and design, acquisition of data, or analysis and interpretation of data; took part in drafting the article or revising it critically for important intellectual content; agreed to submit to the current journal; gave final approval of the version to be published; and agree to be accountable for all aspects of the work.

\section{Disclosure}

The authors have no conflicts of interest to disclose.

\section{References}

1. Jemal A, Siegel R, Xu J, Ward E. Cancer statistics, 2010. CA Cancer J Clin. 2010;60(5):277-300.

2. You YN, Xing Y, Feig BW, Chang GJ, Cormier JN. Young-onset colorectal cancer: is it time to pay attention? Arch Intern Med. 2012;172(3):287-289. doi:10.1001/archinternmed.2011.602

3. Fu JF, Huang YQ, Yang J, Yi CH, Chen HL, Zheng S. Clinical characteristics and prognosis of young patients with colorectal cancer in Eastern China. World J Gastroenterol. 2013;19(44):8078-8084. doi:10.3748/wjg.v19.i44.8078

4. Xingmao Z, Hongying W, Zhixiang Z, Zheng W. Analysis on the correlation between number of lymph nodes examined and prognosis in patients with stage II colorectal cancer. Med Oncol. 2013;30(1):371. doi:10.1007/s12032-012-0371-0

5. Kim CH, Huh JW, Kim HR, Kim YJ. Prognostic comparison between number and distribution of lymph node metastases in patients with right-sided colon cancer. Ann Surg Oncol. 2014;21(4):1361-1368. doi:10.1245/s10434-013-3426-3

6. Zhen ZJ, Ling JY, Cai Y, Luo WB, He YJ. Impact of HLA-E gene polymorphism on HLA-E expression in tumor cells and prognosis in patients with stage III colorectal cancer. Med Oncol. 2013;30(1):482 doi:10.1007/s12032-013-0482-2

7. Corte H, Manceau G, Blons H, Laurent-Puig P. MicroRNA and colorectal cancer. Dig Liver Dis. 2012;44(3):195-200. doi:10.1016/j. dld.2011.10.010
8. Wang Y, Yuan W, Ma X, Ma J. [Expression of microRNA-152 in colorectal cancer and its relationship with prognosis]. Chin J Oncol. 2016;38(10):763-766. Chinese.

9. Ueno H, Mochizuki H, Akagi Y, et al. Optimal colorectal cancer staging criteria in TNM classification. J Clin Oncol. 2012;30 (13):1519-1526. doi:10.1200/JCO.2011.39.4692

10. Chen Y, Gao SG, Chen JM, et al. Serum CA242, CA199, CA125, CEA, and TSGF are biomarkers for the efficacy and prognosis of cryoablation in pancreatic cancer patients. Cell Biochem Biophys. 2015;71(3):1287-1291. doi:10.1007/s12013-014-0345-2

11. Zhou G, Niu L, Chiu D, He L, Xu K. Changes in the expression of serum markers CA242, CA199, CA125, CEA, TNF-alpha and TSGF after cryosurgery in pancreatic cancer patients. Biotechnol Lett. 2012;34(7):1235-1241. doi:10.1007/s10529-012-0908-5

12. Zhao S, Mei Y, Wang Y, Zhu J, Zheng G, Ma R. Levels of CEA, CA153, CA199, CA724 and AFP in nipple discharge of breast cancer patients. Int J Clin Exp Med. 2015;8(11):20837-20844.

13. He CZ, Zhang KH, Li Q, Liu XH, Hong Y, Lv NH. Combined use of AFP, CEA, CA125 and CA19-9 improves the sensitivity for the diagnosis of gastric cancer. BMC Gastroenterol. 2013;13:87. doi: 10.1186/1471-230X-13-87

14. Wray CM, Ziogas A, Hinojosa MW, Le H, Stamos MJ, Zell JA. Tumor subsite location within the colon is prognostic for survival after colon cancer diagnosis. Dis Colon Rectum. 2009;52 (8):1359-1366. doi:10.1007/DCR.0b013e3181a7b7de

15. Hayne D, Brown RS, McCormack M, Quinn MJ, Payne HA, Babb P. Current trends in colorectal cancer: site, incidence, mortality and survival in England and Wales. Clin Oncol. 2001;13(6):448-452.

16. Baek JY, Kang MH, Hong YS, et al. Characteristics and prognosis of patients with colorectal cancer-associated brain metastases in the era of modern systemic chemotherapy. $J$ Neurooncol. 2011;104 (3):745-753. doi:10.1007/s11060-011-0539-z

17. Du F, Shi SS, Sun YK, Wang JW, Chi Y. Clinicopathological characteristics and prognosis of colorectal cancer in Chinese adolescent patients. Chin Med J. 2015;128(23):3149-3152. doi:10.4103/03666999.170256

18. Bozkurt O, Inanc M, Turkmen E, et al. Clinicopathological characteristics and prognosis of patients according to recurrence time after curative resection for colorectal cancer. Asian Pac J Cancer Prev. 2014;15(21):9277-9281. doi:10.7314/APJCP.2014.15.21.9277

19. Kishikawa J, Kawai K, Tsuno NH, et al. Characteristics and prognosis of colorectal cancer associated with rheumatic disease. Int Surg. 2015;100(5):783-789. doi:10.9738/INTSURG-D-14-00154.1
Cancer Management and Research

\section{Publish your work in this journal}

Cancer Management and Research is an international, peer-reviewed open access journal focusing on cancer research and the optimal use of preventative and integrated treatment interventions to achieve improved outcomes, enhanced survival and quality of life for the cancer patient.
The manuscript management system is completely online and includes a very quick and fair peer-review system, which is all easy to use. Visit http://www.dovepress.com/testimonials.php to read real quotes from published authors. 